iatrogenic American culture-bound disorder (!) introduced by suggestion into a willing subject, rather like 'posttraumatic stress disorder'. Tongue in cheek but serious in mind.

University of British Columbia

Edward L. MargetTs

Vancouver, Canada

\section{Medical diplomas}

DeAr Sirs

I read with interest the comments made by Malcolm P. I. Weller in his letter (Bulletin, March 1987, 11, 103) but I think that he may be knocking his head against a brick wall. Although our College is one of the youngest, it already presents with psychomotor retardation of the elderly.

A few years ago, I was annoyed to find that the Royal College of Obstetricians and Gynaecologists was introducing a Diploma in Psychosexual Medicine. My annoyance was mainly because one of the requirements was that the applicants had to have two years gynaecological experience and although I have been running Sexual Dysfunction Clinics for over 15 years, I could not sit the examination for this Diploma. I felt that since the majority of sexual dysfunctions are caused by psychological or psychiatric factors our College should have been introducing such a Diploma.

Gynaecologists exclusively see female patients and although no-one can stop the Royal College of Obstetricians and Gynaecologists from introducing any Diploma they wish, our College should have also introduced a Diploma in Psychosexual Medicine, or least should have asked the Royal College of Obstetricians and Gynaecologists to do away with the requirement for two years gynaecological experience. After all why not have two years experience in urinary surgery-at least urinary surgeons can claim acquaintance with genitals of both sexes. My letter was answered over a year later and the reply by the Registrar was irrelevant to the comments I was making.

The expertise of other branches of medicine can be practised only by the relevant medical practitioners but for psychiatric patients all sorts of experts are available. Every Tom, Dick and Harry can set up shop and claim to be Hypnotherapists, Psychoanalysts, Hypnoanalysts, Counsellors, Therapists, Sexual Therapists, Acupuncturists, Herbalist, Homeopathic Therapists, Acupressure Therapists, Aroma Therapists and so on. They can advertise themselves in the local press and attract clients who by the nature of their illnes are already vulnerable.

Only the Royal College of Psychiatrists is equipped because of its expertise to organise research on these forms of therapies to prove their effectiveness or ineffectiveness, and if some of the therapies are effective, to introduce its own relevant Medical Diplomas, for example, Diploma in Medical Acupuncture, Dipolma in Medical Hypnotherapy, Diploma in Medical Psychosexual Counselling, etc.

Billinge Hospital

B. P. Maragakis

Billinge, near Wigan

\section{DEAR SIRS}

We have investigated the diploma that Dr Maragakis reported. However, we found that he was misinformed. The diploma was not being introduced by the Royal College of Obstetricians and Gynaecologists, nor by any of our sister Colleges, but by an independent academic body. Thus, although we have some sympathy with Dr Maragakis' concern, we could not intervene in the situation.

R. G. PRIEST Registrar

\title{
MIND Book of the Year 1987 \\ The Allen Lane Award
}

MIND, the leading mental health charity, awards a $£ 1,000$ prize each year to the book which makes the greatest contribution to public understanding of mental illness or mental handicap. Nominations are particularly invited for works of fiction or non-fiction which describe the prevention, causes, treatment or experience of mental illness or mental handicap in an easy to read, non-technical style.

This special award was inaugurated in 1981 in memory of Allen Lane and is supported by the Allen Lane Foundation. Past winners include The Art of Starvation by Sheila
MacLeod, Depression-The Way Out of Your Prison by Dorothy Rowe, $A$ Woman in Custody by Audrey Peckham and Talking To A Stranger-A Consumer's Guide to Therapy by Lindsay Knight.

The closing date for nominations is 5 October 1987. The winning entry will be announced at MIND's Annual Conference on 23 November 1987.

Nomination details and forms available from Christine Shaw, Assistant Director, MIND, 22 Harley Street, London WIN 2ED (telephone: 01637 0741). 